\title{
Decompression Haematuria from Upper Urinary Tract: A Rare Complication
}

\author{
Praveen Pushkar* \\ Asian Institute of Medical Sciences, India \\ *Corresponding author: Praveen Pushkar, Asian Institute of Medical Sciences, Faridabad, India
}

Submission: 瑇 October 31, 2018; Published: 制 November 21, 2018

Abstract

In cases of chronic urinary retention, post decompression diuresis and haematuria are well known complications. Majority of cases of decompression haematuria resolves spontaneously. Rarely haematuria is so much that blood transfusion is required. In all the cases reported in literature haematuria occurs as generalized oozing from bladder mucosa after decompression. In the case described below there was isolated bleeding from both renal pelvis rather than bladder mucosa which resulted in obstructive renal failure.

Keywords: Decompression haematuria; Obstructive nephropathy; BPH; Blood transfusion

\section{Case Presentation}

A 67-year male had history of lower urinary tract symptoms for last two years but has not started any treatment for that. He developed urinary retention for which urethral catheterization was done in primary health centre and was referred to our hospital. Approximately 2.5 litres of urine was drained at the time of catheterization. Before catheterisation his ultrasonography was done which revealed bilateral moderate hydroureteronephrosis with overdistended urinary bladder and gross prostatoegaly (96grams). At the time of presentation in our hospital, he was clinically stable with clear urine draining in the Foley catheter. His S. Creatinine was $5.86 \mathrm{mg} / \mathrm{dL}, \mathrm{S} . \mathrm{K}+5.9 \mathrm{mEq} / \mathrm{L}$ and haemoglobin $7.8 \mathrm{~g} / \mathrm{dL}$. There was no leucocytosis. His urine output was 150 to $200 \mathrm{~mL} /$ hour on $1^{\text {st }}$ day post catheterisation. Haemodialysis was done on $2^{\text {nd }}$ day of admission for rising potassium level. On third day of admission patient developed gross haematuria and hourly urine output decreased suddenly to 20 to $30 \mathrm{~mL} /$ hour.Two-way Foley catheter was replaced with three-way catheter and bladder irrigation was started. His haemoglobin level came down to $4.5 \mathrm{~g} /$ $\mathrm{dL}$. He was given two units of PRBCs and bed side ultrasonography was done. Ultrasonogram showed gross hydronephrosis in both kidneys (Right $>$ Left).

Non-contrast CT scan of KUB region was done on urgent basis which showed bilateral gross hydroureteronephrosis with echogenic foci suggestive of blood clots in pelvis of both the kidneys and hypertrophy of bladder wall (Figure 1) [1]. He was taken up for cystoscopy with bilateral DJ stenting. Cystoscopy showed gross obstructive prostatomegaly with multiple wide mouth bladder diverticuli and trabeculations. There was no lesion or clots in bladder. There was no oozing from prostate or bladder mucosa.
Efflux from both the ureteric orifices showed blood tinged urine. Retrograde pyelogram (RGP) was done bilaterally which showed grossly dilated and tortuous ureter on both sides. Lower ureter was not dilated. Upper two-thirds of ureter was grossly dilated and were making loops. No stones or urothelial lesions were seen. 6/26 DJ stent was placed bilaterally. On right side stent reached till upper ureter only due to tortuosity. Percutaneous nephrostomy was also done on right side with 12 Fr PCN tube as DJ stent could not reach the pelvis. Blood tinged urine started coming from PCN tube. His blood parameters started improving following the procedure. After $4^{\text {th }}$ post-operative day his urine became clear and urine output became stable at around $100 \mathrm{~mL} /$ hour. At the time of discharge his serum creatinine value stabilised at $2.3 \mathrm{mg} / \mathrm{dL}$.

\section{Discussion}

Haematuria is known complication post catherization in chronic urinary retention. Gross haematuria is seen in 2 to 16 $\%$ of cases. In most of the cases haematuria develops within few hours of decompression unlike this case. In clinical practice, in majority of cases haematuria resolves by itself and seldom requires blood transfusion [2]. In this case baseline haemoglobin level was low so blood transfusion was required. This was atypical presentation of decompression haematuria in many ways. First haematuria developed on third day of catheterisation. Second, there was significant haematuria which resulted in significant fall in haemoglobin level. Third and the most important one is decompression haematuria occurred from both renal pelvis rather than bladder mucosal surface. I have searched the literature but I could just find one single case report of bleeding from upper urinary tract after bladder decompression [3]. 


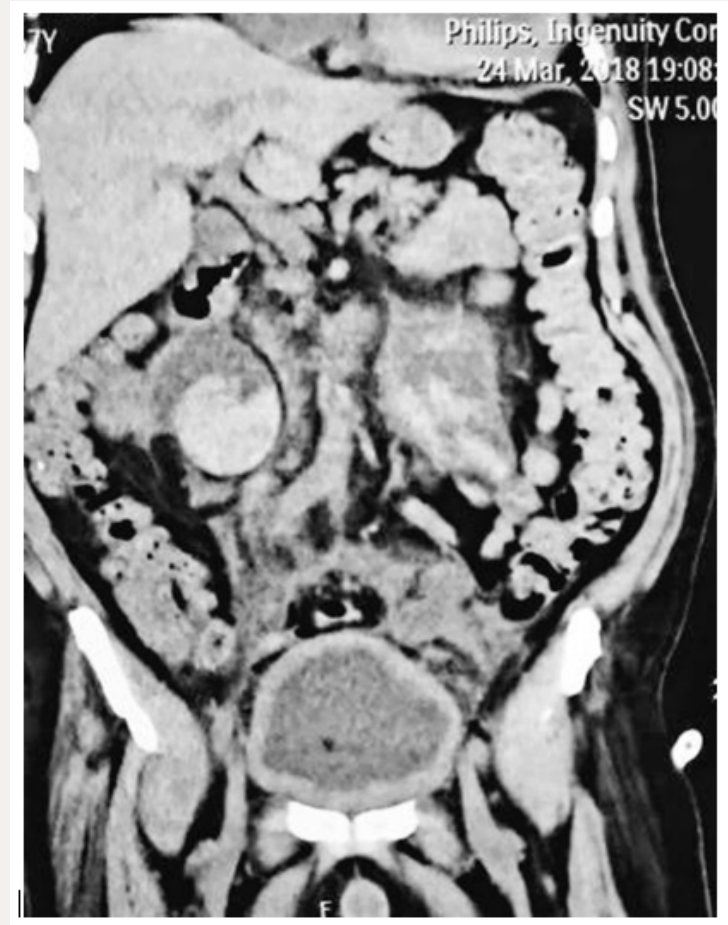

Figure 1: CT scan showing bilateral hydronephrosis with clots in both renal pelvis.

Pathological process which is seen in chronic urinary retention in bladder affecting the integrity of capillaries might affect upper tract too. So, there is a possibility of bleeding from any urothelial surface from renal pelvis to bladder mucosa. Decompression haematuria results from urothelial trauma due to overdistention and subsequent decompression. This usually resolves spontaneously within 48 to 72 hours. Rarely bladder irrigation and washouts are required. A randomized trial compared rapid versus gradual decompression post urinary retention and found no statistical significant difference of haematuria between both groups [4].

\section{Conclusion}

Decompression haematuria from upper urinary tract resulting in obstructive nephropathy is extremely rare. This should be kept in mind in cases of decompression haematuria with deteriorating renal function.

\section{References}

1. Nyman MA, Schwenk NM, Silverstein MD (1997) Management of urinary retention: Rapid versus gradual decompression and risk of complications. Mayo Clin Proc 72(10): 951-956.

2. Soylu A, Kavukçu S, Türkmen M, Arici A, Aktud T (2000) Hematuria as a complication of sudden decompression of chronically distended bladder in a child with neurogenic bladder dysfunction. Pediatr Emerg Care 16(3): 221.

3. Naranji I, Bolgeri M (2012) Significant upper urinary tract haematuria as a rare complication of high-pressure chronic retention of urine following decompression: A case report. J Med Case Rep 6: 254.

4. Boettcher S, Brandt AS, Roth S, Mathers MJ, Lazica DA (2013) Urinary retention: Benefit of gradual bladder decompression - myth or truth? A randomized controlled trial. Urol Int 91(2): 140-144.
Creative Commons Attribution 4.0 International License

For possible submissions Click Here

\section{Submit Article}

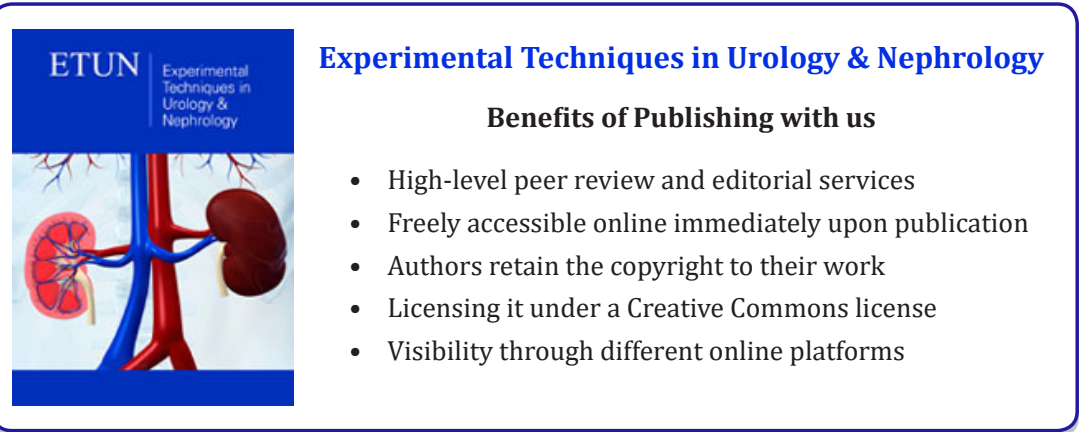

